\title{
Agreement between mothers', fathers', and children's' ratings on health-related quality of life in children born with esophageal atresia - a German cross-sectional study
}

Stefanie Witt ${ }^{1 *}$ D, Janika Bloemeke ${ }^{1}$, Monika Bullinger ${ }^{1}$, Jens Dingemann ${ }^{2}$, Michaela Dellenmark-Blom ${ }^{3}$ and Julia Quitmann'

\begin{abstract}
Background: Esophageal atresia (EA) is a rare congenital malformation, which is characterized by the discontinuity of the esophagus. We investigated the agreement between mothers', fathers', and children's' ratings on health-related quality of life (HRQOL) in children born with EA. We aimed to broaden the understanding of subjective experiences of $\mathrm{HRQOL}$ from different perspectives. We hypothesized that the agreement between mother and father ratings would be high, whereas the agreement between child and mother ratings as well as child and father ratings would show more substantial differences.

Methods: We obtained data from 40 families (23 mother-father dyads of children aged 2-7 years and 17 motherfather-child triads of children and adolescents aged 8-18years) with children born with EA, who were treated in two German hospitals. HRQOL was measured using the generic PedsQL ${ }^{\mathrm{TM}}$ questionnaires and the condition-specific EA-QOL@ questionnaires. We calculated intraclass coefficients and performed one-way repeated measures ANOVAs to analyze differences for each domain as well as for the total scores.

Results: Intraclass correlation coefficients (ICCS) indicated a strong agreement $(\geq .80)$ between mother and father reports of children's HRQOL for both generic and condition-specific measurements. The ICCs for the generic HRQOL for mother/father-child-dyads revealed only fair to good agreement, whereas ICCs for condition-specific HRQOL showed high agreement for mother-child and father-child-agreement. Analyses of Covariance revealed differences in mother/father-child agreement in the generic domain School, both parents reporting lower HRQOL scores than the children themselves. Fathers reported significantly higher scores in the condition-specific domain Social than their children.

(Continued on next page)
\end{abstract}

\footnotetext{
* Correspondence: s.witt@uke.de

${ }^{1}$ Department of Medical Psychology, University Medical Center

Hamburg-Eppendorf, Center for Psychosocial Medicine, Martinistraße 52, W

26, 20246 Hamburg, Germany

Full list of author information is available at the end of the article
}

(c) The Author(s). 2019 Open Access This article is distributed under the terms of the Creative Commons Attribution 4.0 International License (http://creativecommons.org/licenses/by/4.0/) which permits unrestricted use, distribution, and reproduction in any medium, provided you give appropriate credit to the original author(s) and the source, provide a link to the Creative Commons license, and indicate if changes were made. The Creative Commons Public Domain Dedication waiver (http://creativecommons.org/publicdomain/zero/1.0/) applies to the data made available in this article, unless otherwise stated. 
(Continued from previous page)

Conclusions: Results showed that mothers' and fathers' reports corresponded to each other. Nonetheless, these reports might not be interchangeably used because mother-child and father-child agreement showed differences. Children might know the best on how they feel, and parent proxy-report is recommended when reasons such as young age, illness, or cognitive impairments do not allow to ask the child. But parent-report - no matter if reported by mother or father - should only be an additional source to broaden the view on the child's health status and well-being. The current study contributes to a better understanding of the complex family relationships involved when parenting a child born with EA.

Keywords: Interrater-agreement, Health-related quality of life, Children, Parents, Self- and proxy-report, Rare disease, Esophageal atresia

\section{Background}

Esophageal atresia (EA) is a rare congenital malformation, which is characterized by the discontinuity of the esophagus. The prevalence varies between 1 and 2 in 5000 live births in Europe [1-3]. EA can be divided into different subtypes, with the majority of cases showing a connection between the esophagus and the windpipe. Most commonly, the affected children undergo surgical correction of the esophagus within a few days after birth. In more complicated cases, when the anatomic gap is too long, surgery may be delayed several months $[1,3,4]$.

The prognosis on survival in infants born with EA has reached over 90\% [1-4]. Nevertheless, long-term morbidity of EA patients remains both frequent and complicated. These complications are persisting into adulthood [5]. Studies demonstrate that morbidity among EA survivors results in swallowing difficulties [6], gastroesophageal reflux which can lead to symptoms such as vomiting, heartburn, cough and regurgitation [7-12] chronic and/or barky cough, wheezing and recurrent respiratory infections [13], as well as asthma, are frequently seen in patients [6, 13-15]. Additional morbidity can result from co-existing anomalies, which are present in approximately onehalf of EA patients [16].

Accordingly, the disease and its treatment can have significant impacts on the individual and his/her family, and increased attention has been paid to the patient-reported outcomes (PRO's), especially the patients' healthrelated quality of life (HRQOL).

HRQOL is an individual's subjective perception of the impact of health status, including disease and treatment, on, e.g., physical, social, emotional functioning [17]. Dellenmark-Blom, Chaplin [18] have recently published a comprehensive review of the HRQOL of patients with EA. Accordingly, EA may be associated with reduced HRQOL, but several studies described inconsistent results about HRQOL of children born with EA.

Due to a lack of a cross-cultural available and valid instrument to measure HRQOL from the patients and parents perspective, a German-Swedish cooperation study was performed to develop and validate such a condition-specific instrument [19-22].

PRO's, esp. HRQOL questionnaires are increasingly used in clinical practice and research for evaluation of the children's health status [23]. In addition to medical information, knowledge of the HRQOL of a child born with EA is essential for treatment decisions, the assessment of the course of therapy, and the assessment of the therapeutic success [24, 25].

Since it is relevant to identify a reliable and valid source of information [26] the ongoing discussion on whom to ask for the assessment on children's HRQOL is important from both the scientific and clinical perspective. Children are increasingly asked to provide a self-assessment of their HRQOL [27]. If the child is too young, ill, or due to cognitive impairments, the parent proxy-report is required, and usually the only source of information [24]. Children aged 8 or more can complete selfreports of HRQOL $[28,29]$ and it is important to give them the opportunity to report their own subjective experiences of health and well-being [30, 31], even if they need assistance in reading. Parental proxy-reports remain the most frequent source of additional information on children's wellbeing and functioning [27].

In other pediatric health conditions, different studies have investigated the maternal/paternal report of children's emotional and behavioral functioning, showing a stronger correspondence in parents than in other cross-informant pairs (such as parent-child, parent-teacher) [32-35].

Nevertheless, discrepancies are found between mothers' and fathers' ratings with again inconsistent findings: while some studies show that mothers focus more on symptoms/problems than fathers, other studies reveal no differences in problem severity between mothers' and fathers' ratings [35-37].

In usual pediatric settings, health care professionals and researchers often meet only one parent, it is less common to meet both parents. In the majority, mothers are usually the prime informant [38]. Still, the need to examine mother-father (dis-) agreement of children's 
HRQOL aligns with the broader need to more regularly include fathers in child development and psychopathology research [35]. However, it is well known that children's self-report and parent proxy-report of HRQOL are not interchangeable [39-41] and imperfect agreement between children and parents has been consistently demonstrated in the HRQOL measurement of children with chronic health conditions and healthy children [31, 42-44].

There are very few studies available that include the perspectives of children, mothers, and fathers to assess the children's HRQOL and the understanding of mother and father agreement or discrepancies of their children's HRQOL is needed for a comprehensive and entire view of the child's HRQOL. Therefore, we aimed to assess the inter-rater-agreement in a clinical sample of children and adolescents born with EA for mother, father, and child ratings of generic and condition-specific HRQOL. On the one hand, we hypothesized that the agreement between mother and father ratings would be high, whereas the agreement between child and mother ratings as well as child and father ratings would show more significant differences. On the other hand, we expected differences regarding the level of agreement depending on the investigated HRQOL domains.

\section{Methods}

The study was a part of a cross-cultural Swedish-German project aiming to develop a condition-specific questionnaire to measure HRQOL in children and adolescents born with EA [19-21]. The Ethical Review Board of Hannover, Germany (2936-2015) approved the study. Within this specific part of the study, we focus on the parental (dis-) agreement of young (2-7 years) children born with EA and the (dis-) agreement of mothers, fathers, and children (8-18 years). All children and adolescents who were treated for EA prior to 2016 either at the Medical School Hannover (MHH) or the Child Hospital 'Auf der Bult' as well as their parents were invited to participate. Inclusion criteria included children being between 2 and 17 years old at assessment and being diagnosed with EA. Exclusion criteria were insufficient German language proficiency, missing contact data, and missing clinical data.

A total of 102 eligible families were contacted between September and November 2016. A local researcher contacted the families and gave them oral and written study information. After the family gave written study approval, medical records were reviewed for clinical data, and questionnaires were sent home to the family with pre-stamped envelopes for their replies. Parents provided written consent for children and adolescents under the age of 16 years. They received a maximum of three reminders to return the questionnaires to increase response rate.

\section{Data collection}

We measured generic child self-reported and parent proxy-reported HRQOL using the PedsQL ${ }^{\mathrm{Ta}}$ questionnaire [45]. The questionnaire includes 23 items, assessing Physical, Emotional, Social, and School Functioning, and can be calculated in the three summary scores (Total Scores, Physical Health Summary Score, and Psychosocial Health Summary Score) with higher scores indicating better HRQOL. In the current sample, Cronbach's alpha values were ranging from .72 (Social Functioning, mother-report) to .89 (Physical Functioning, mother-report; Total Score, child-report).

To assess condition-specific HRQOL, we used the EA-

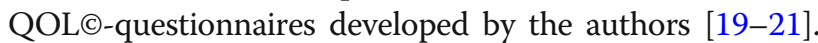
The 17-item EA-QOL@ questionnaire for parents of children 2-7years of age includes three domains; Eating, Physical health \& Treatment, and Social isolation \& Stress. In the current sample, the domains for parents of younger children showed acceptable to good reliability with Cronbach's alpha values ranging from .73 (Eating, father-report) to .88 (Physical, mother-report). The 24-item EAQOL○ questionnaires for children and parents of children 8-17 years of age includes four domains; Eating, Social relationships, Body perception, and Health \& Well-being, additionally a Total Score can be calculated from all domains; higher scores indicated better HRQOL. Acceptable to good reliability was also found in the current sample for the 24-item EA-QOL $\odot$ questionnaires, with Cronbach's $\alpha$ values ranging from .74 (Eating, father-report) to .91 (Physical, mother-report).

Additionally, we requested the parents to answer questions on sociodemographic data. Clinical variables were provided from medical records.

\section{Data analysis}

For all statistical analysis, we used the IBM Statistical Package for Social Sciences Statistics version 25 [46]. We calculated means and standard deviations (SD) for each HRQOL domain. Except for sociodemographic and clinical variables, we replaced missing values by the individual mean score for each variable if missing data were random and less than $30 \%$ of the values (EAQOL○) respectively $50 \%$ of the values $\left(\right.$ PedsQL $\left.^{\mathrm{m}}\right)$. The proportion of missing values in the current sample was less than $20 \%$.

To investigate the inter-parental (dis-) agreement, respectively mother-child and father-child agreement on domain levels and for the total scores on an individual level, we calculated intraclass correlation coefficients (ICCs). The level of agreement is preferable evaluated by the ICCs estimate's 95\% confidence interval (CI) [47]. ICC values < .40, were interpreted as poor agreement, between .40 and .59 as fair agreement, ICC values between .60 and .74 as good agreement and values $\geq .75$ represented excellent 
agreement [48]. The significance level was set to be less than $.05(p \leq .05)$.

We performed one-way repeated measures ANOVAs to analyze differences between mother and father mean scores, respectively mother and child mean scores, as well as father and child mean scores for each domain as well as for the total scores on a group level. We entered the perspectives (mother vs. father resp. mother vs. child and father vs. child) as the within-subjects factors and children's age and children's gender as covariates into the model.

\section{Results}

The study sample for the present analyses included 80 parents of 40 children and adolescents born with EA aged between 2 to 18 years of age ( 23 mother-father dyads of children aged 2-7 years and 17 mother-father- child triads of children and adolescents aged 8-18 years).

The mean age for mothers was 40.7 years $( \pm 7.78)$, for fathers 43.1 years $( \pm 8.82)$. Higher education (12 years or even a university degree) was present in $69.2 \%$ of the mothers and $57.6 \%$ of the fathers. $65.8 \%$ of the mothers worked part-time, none full time. $90 \%$ of the fathers worked full time, $10 \%$ part-time. Out of the 40 children and adolescents, $22(55 \%)$ were males aged between 2 and 18 years old $\left(\mathrm{M}_{\text {age }}=8.03, \pm 4.45\right)$. According to predefined criteria [19], 24 (60\%) of the children showed a mild-moderate severity level of EA, 16 (40\%) showed severe disease characteristics. Except for one family, both parents live together in a household with the child.

Means and standard deviations for all HRQOL domains are presented in Table 1 . Almost all values score in the upper segment of the 0-100 transformed scales with means ranging from 64.08 (mother-reported

Table 1 Mean scores, standard deviation and ANCOVA for repeated measures for mother, father and child-reported children's $\mathrm{HRQOL}$

\begin{tabular}{|c|c|c|c|c|c|c|c|c|c|c|c|c|c|}
\hline \multirow[t]{3}{*}{ HRQOL } & & \multicolumn{4}{|c|}{ Mother and father reports $(n=40)$} & \multicolumn{4}{|c|}{ Mother and child reports $(n=16)$} & \multicolumn{4}{|c|}{ Father and child reports $(n=16)$} \\
\hline & & \multirow[t]{2}{*}{$\mathrm{n}$} & \multirow{2}{*}{$\begin{array}{l}\text { Mother } \\
\text { M (SD) }\end{array}$} & \multirow{2}{*}{$\begin{array}{l}\text { Father } \\
\text { M (SD) }\end{array}$} & \multirow[t]{2}{*}{$p$} & \multirow[t]{2}{*}{$n$} & \multirow{2}{*}{$\begin{array}{l}\text { Mother } \\
\text { M (SD) }\end{array}$} & \multirow{2}{*}{$\begin{array}{l}\text { Child } \\
\text { M (SD) }\end{array}$} & \multirow[t]{2}{*}{$p$} & \multirow[t]{2}{*}{$n$} & \multirow{2}{*}{$\begin{array}{l}\text { Father } \\
\text { M (SD) }\end{array}$} & \multirow{2}{*}{$\begin{array}{l}\text { Child } \\
\text { M (SD) }\end{array}$} & \multirow[t]{2}{*}{$p$} \\
\hline & & & & & & & & & & & & & \\
\hline \multicolumn{14}{|l|}{ Generic } \\
\hline \multirow[t]{6}{*}{$2-7$ yrs } & Physical & 23 & $80.93(20.91)$ & $78.51(20.67)$ & .32 & & na & na & & & na & na & \\
\hline & Social & 23 & $81.52(18.92)$ & $80.80(20.34)$ & .56 & & na & na & & & na & na & \\
\hline & Emotional & 23 & $64.08(18.15)$ & $71.03(18.49)$ & $.04 *$ & & na & na & & & na & na & \\
\hline & School & 22 & $71.52(21.09)$ & $75.91(19.48)$ & .22 & & na & na & & & na & na & \\
\hline & Psychosocial & 23 & $71.63(15.12)$ & 75.69 (15.66) & .13 & & na & na & & & na & na & \\
\hline & Total & 23 & $74.72(15.33)$ & 76.59 (16.24) & .40 & & na & na & & & na & na & \\
\hline \multirow[t]{6}{*}{$8-18$ yrs } & Physical & 16 & 84.38 (18.49) & $88.37(12.30)$ & .21 & 16 & 87.89 (11.85) & $91.41(11.44)$ & .29 & 16 & $90.54(8.70)$ & $91.41(11.44)$ & .75 \\
\hline & Social & 17 & $88.75(14.43)$ & $91.25(10.72)$ & .30 & 16 & $88.75(14.43)$ & $88.44(14.80)$ & .93 & 16 & 91.25 (10.72) & $88.44(14.80)$ & .46 \\
\hline & Emotional & 16 & 81.84 (18.76) & 83.97 (18.44) & .46 & 15 & $82.33(18.21)$ & $89.00(17.55)$ & .10 & 15 & $86.00(14.54)$ & $89.00(17.55)$ & .49 \\
\hline & School & 17 & 71.47 (17.66) & $68.24(17.76)$ & .30 & 16 & $72.50(17.70)$ & 82.19 (12.78) & $.02 *$ & 16 & $68.13(18.34)$ & 82.19 (12.78) & $\leq .01^{* *}$ \\
\hline & Psychosocial & 17 & 79.39 (16.49) & 79.99 (13.16) & .75 & 15 & 81.78 (14.78) & 87.00 (11.59) & .10 & 15 & $82.02(10.91)$ & 87.00 (11.59) & .07 \\
\hline & Total & 17 & $81.11(16.56)$ & 82.91 (11.89) & .39 & 15 & $84.13(13.20)$ & 88.06 (10.46) & .18 & 15 & $85.27(8.83)$ & 88.06 (10.46) & .25 \\
\hline \multicolumn{14}{|c|}{ Condition-specific } \\
\hline \multirow[t]{4}{*}{$2-7$ yrs } & Eating & 19 & 71.55 (13.27) & 73.50 (13.75) & .45 & & na & na & & & na & na & \\
\hline & Body & 22 & $64.51(26.73)$ & $69.58(25.71)$ & .06 & & na & na & & & na & na & \\
\hline & Social & 19 & $84.21(21.89)$ & $85.20(22.56)$ & .77 & & na & na & & & na & na & \\
\hline & Total & 21 & $70.26(20.58)$ & 73.85 (19.53) & .12 & & na & na & & & na & na & \\
\hline \multirow[t]{5}{*}{$8-18$ yrs } & Eating & 14 & $73.66(18.21)$ & 72.51 (18.86) & .69 & 14 & $73.66(18.21)$ & 75.70 (20.95) & .47 & 15 & 72.47 (18.18) & $74.20(21.01)$ & .54 \\
\hline & Social & 14 & 80.36 (18.94) & $86.22(17.77)$ & $.01 * *$ & 14 & 80.36 (18.94) & 78.32 (21.90) & .53 & 15 & $86.43(17.14)$ & 79.05 (21.30) & $.03^{*}$ \\
\hline & Body & 15 & $84.33(22.43)$ & 85.33 (19.13) & .60 & 15 & $84.33(22.43)$ & 91.00 (18.05) & .18 & 15 & 85.33 (19.13) & 91.00 (18.05) & .16 \\
\hline & Health & 15 & $87.50(16.37)$ & 88.33 (19.89) & .81 & 15 & 87.50 (16.37) & $84.58(23.25)$ & .50 & 15 & 88.33 (19.87) & $84.58(23.25)$ & .16 \\
\hline & Total & 14 & 79.99 (16.51) & 82.02 (16.61) & .14 & 14 & 79.99 (16.51) & 80.98 (18.22) & .52 & 15 & 81.97 (16.01) & 80.85 (17.56) & .48 \\
\hline
\end{tabular}

Covariates included in the model: children's age and children's gender $M$ Mean, SD Standard deviation, $p P$-value, na Not applicable

${ }^{*} p \leq .05 ;{ }^{* *} p \leq .01$ 
generic HRQOL, Emotional, 2-7 years) to 91.41 (childreported generic HRQOL, Physical, 8-18 years). Mother reported lower HRQOL than fathers in almost all domains; except the generic domains Physical and Social (2-7 years) as well as the condition-specific domain Eating (8-18 years). The lowest average HRQOL mean scores for mother-reported HRQOL appeared on the generic domain Emotional for 2-7 years-old children $(M=64.08)$, for father-reported HRQOL on the condition-specific domain Body and Health for 2-7 years-old children $(M=69.59)$ and for child-reported HRQOL the lowest mean scores appeared on the condition-specific domain Eating $(\mathrm{M}=74.20)$.

On a group level, analyses of covariance for repeated measures (ANCOVA) showed significant differences between mother- and father-reported children's HRQOL for two HRQOL domains; generic domain Emotional for 2-7-years-old $(F=5.01, p=.04)$ and condition-specific HRQOL domain Social for 8-18-years-old $(F=8.59$, $p=.01)$. All other domains and total scores showed no significant differences between mother and father- reported HRQOL. Differences between maternal and children's mean scores on a group level were found for the generic domain School $(F=7.58, p=.02)$. For paternal and children's mean scores, our analysis showed significant differences for the generic domain School $(F=$ $15.26, p \leq .01)$ and the condition-specific domain Social $(F=5.57, p=.03)$ (Table 1).

On an individual level, ICCs indicated a strong agreement $(\geq .80)$ between mother and father reports of children's HRQOL for both generic and condition-specific measurements. The lowest ICCs we found for the generic HRQOL domain Emotional (2-7-years-old) and the generic HRQOL domain Physical (8-18-years-old) with 80 . The highest ICCs we found for the condition-specific domain Body (8-18-years-old) and the condition-specific Total score (8-18-years-old) with .97 (Table 2).

The agreement on individual level for mother-childdyads showed excellent agreements for the condition-specific HRQOL measurement with the lowest ICCs for the domain Body \& Health (.75) and the highest agreement for the Total Score (.97). The ICCs for the generic

Table 2 Inter-rater reliability: intraclass correlation coefficients for mother-father agreement, mother-child agreement, and fatherchild agreement

\begin{tabular}{|c|c|c|c|c|c|c|c|c|}
\hline \multirow[t]{2}{*}{ HRQOL } & & & \multicolumn{2}{|c|}{ Mother and father reports } & \multicolumn{2}{|c|}{ Mother and child reports } & \multicolumn{2}{|c|}{ Father and child reports } \\
\hline & & & $\overline{\mathrm{ICCS}^{\mathrm{a}}}$ & {$[\mathrm{Cl}]$} & $\overline{\mathrm{ICCS}^{\mathrm{a}}}$ & {$[\mathrm{Cl}]$} & $\mathrm{ICCS}^{\mathrm{a}}$ & {$[\mathrm{Cl}]$} \\
\hline \multirow[t]{12}{*}{ Generic } & $2-7$ yrs & Physical & $.94^{* *}$ & {$[.85-.97]$} & na & na & na & na \\
\hline & & Social & $.90^{* *}$ & {$[.77-.96]$} & na & na & na & na \\
\hline & & Emotional & $.80^{* *}$ & {$[.50-.92]$} & na & na & na & na \\
\hline & & School & $.91^{* *}$ & {$[.78-.96]$} & na & na & na & na \\
\hline & & Psychosocial & $.87^{* *}$ & {$[.69-.95]$} & na & na & na & na \\
\hline & & Total & $.93^{* *}$ & {$[.83-.97]$} & na & na & na & na \\
\hline & $8-18$ yrs & Physical & $.80^{* *}$ & {$[.47-.93]$} & .57 & {$[-.18-.85]$} & $.64^{*}$ & {$[-.08-.86]$} \\
\hline & & Social & $.84^{* *}$ & {$[.57-.95]$} & $.70^{*}$ & {$[.10-.90]$} & .49 & {$[-.47-.82]$} \\
\hline & & Emotional & $.89^{* *}$ & {$[.71-.96]$} & $.78^{* *}$ & {$[.38-.93]$} & $.66^{*}$ & {$[-.03-.89]$} \\
\hline & & School & $.86^{* *}$ & {$[.62-.95]$} & $.67^{* *}$ & {$[.06-.88]$} & $.60^{* *}$ & {$[-.17-.86]$} \\
\hline & & Psychosocial & $.93^{* *}$ & {$[.82-.98]$} & $.74^{* *}$ & {$[.34-.91]$} & $.74^{* *}$ & {$[.25-.91]$} \\
\hline & & Total & $.91^{* *}$ & {$[.76-.97]$} & $.73^{* *}$ & {$[.24-.91]$} & $.71^{*}$ & [.18-.90] \\
\hline \multirow[t]{9}{*}{ Condition-specific } & $2-7$ yrs & Eating & $.81^{* *}$ & {$[.50-.93]$} & na & na & na & na \\
\hline & & Body & $.94^{* *}$ & {$[.84-.98]$} & na & na & na & na \\
\hline & & Social & $.88^{* *}$ & {$[.70-.96]$} & na & na & na & na \\
\hline & & Total & $.93^{* *}$ & {$[.82-.97]$} & na & na & na & na \\
\hline & $8-18$ yrs & Eating & $.92^{* *}$ & {$[.75-.97]$} & $.93^{* *}$ & [.79-.98] & $.93^{* *}$ & [.78-.98] \\
\hline & & Social & $.94^{* *}$ & {$[.67-.98]$} & $.91^{* *}$ & {$[.73-.97]$} & $.86^{* *}$ & [.74-.96] \\
\hline & & Body & $.97^{* *}$ & {$[.92-.99]$} & $.75^{* *}$ & {$[.25-.91]$} & $.81^{* *}$ & [.44-.93] \\
\hline & & Health & $.86^{* *}$ & {$[.57-.95]$} & $.81^{* *}$ & {$[.43-.94]$} & $.94^{* *}$ & {$[.83-.98]$} \\
\hline & & Total & $.97^{* *}$ & {$[.93-.99]$} & $.97^{* *}$ & {$[.91-.99]$} & $.97^{* *}$ & {$[.91-.99]$} \\
\hline
\end{tabular}

ICC Intraclass correlation coefficient (two-way mixed model. Absolute agreement, $\mathrm{Cl} 95 \%$ confidence interval, na Not applicable

${ }^{*} p \leq .05 ;{ }^{* *} p \leq .01$

${ }^{\mathrm{a}}$ Intraclass correlation coefficients reference values: ICC $<.40=$ poor agreement, ICC between .41 and $.60=$ moderate agreement, ICC between .61 and $.80=$ good agreement, ICC $>.81=$ excellent agreement [49] 
HRQOL for mother-child-dyads revealed only fair to good agreement. Only for the generic domain Emotional, the ICCs showed excellent agreement (.78). Analyzing fatherchild-dyads, we found high agreement for the conditionspecific HRQOL measurement between .81 and .97 . The father-child-agreement on generic HRQOL revealed fair to good results with the lowest ICCs for the generic domain Social (.49) (Table 2).

\section{Discussion}

From our point of view, it is crucial to measure HRQOL from the perspectives of different family members. So far, only few research studies have included multiple family members, and to our knowledge, this is the first study aiming to investigate the agreement between mothers, fathers, and child-reported HRQOL in a sample of children born with EA. We assessed parental perceptions of HRQOL of their children born with EA as well as children's perceptions. We compared mothers' and fathers' reports on children's HRQOL as well as mothers'/fathers' and children's report to examine the level of agreement respectively differences using generic as well as condition-specific measurements.

Measuring congruence beyond dyadic relationships addresses this family science research gap and contributes to this body of literature because study findings suggest multiple family members do not always perceive HRQOL alike [50, 51].

It is challenging to define, conceptualize, interpret, measure, and improve HRQOL because HRQOL is subjective, and patients and parents identify fundamentals they feel are important to their HRQOL [52-55]. Studying the different perspectives from multiple family members involved in the children's health care process is important because of the above-mentioned inconsistencies in the literature, which reveal that the children's perception of HRQOL might vary from their family members' perceptions. This variation has clinical (e.g., regarding the focus of treatment for children and each parent) as well as research implications (e.g., regarding possible differences on the definition of HRQOL the families, since we do not know if family members disagree on the definition of HRQOL or only on how to quantify it). Therefore, congruence regarding HRQOL is important to the long-term well-being of families with children suffering from rare chronic diseases, but parents and health providers should be aware of differences in the perception of HRQOL from different family members.

Results of our study showed strong inter-parental agreement on individual level across all dimensions for both generic and condition-specific HRQOL. On group level, we found no significant differences between maternal and paternal report. Only for the generic domain
Emotional (2-7 years) and the condition-specific domain Social, we found a significant difference between mother and father report, showing that fathers reported higher HRQOL scores than mothers.

These high mother-father agreements are in line with current research, that reported moderate to strong agreements [35, 37, 50, 57-59]. But while most studies investigated internalizing and externalizing behavior, only two studies are available, that focused on inter-parental agreement of parent-reported child HRQOL [56, 60]. These samples consisted of parents of children with mental disorders in a clinical setting or parents of healthy children. Only one study included parents of chronically ill children [60].

Nonetheless, our findings of high inter-parental agreement do not imply that maternal and paternal reports might be used interchangeably.

The ICCs for mother-child-reports as well as fatherchild-reports revealed higher agreement for the condition-specific measurements, with an excellent agreement for all domains except mother-child agreement on the condition-specific domain Body Perception. However, the agreement for the generic HRQOL showed only moderate to good agreement. Contrary to current literature, the parent-child agreement did not show higher ICCs for the domain Physical [24, 41]. The different results of parent-child agreement depending on the used measurement might be explained by the need to communicate about disease-specific demands [61] and a high degree of parental awareness of disease-specific aspects of children's daily life.

Both mothers and fathers tended to underrate the children's generic HRQOL regarding the domain School. This domain assesses aspects of absentee days in school and the ability to concentrate on school works. This significant underrating of children's HRQOL in the domain School shows that parents of children born with EA might assess the disease-specific effects of EA on the child's daily life significantly higher than the children. Silva, Bullinger [62] reported significantly higher ICCs for parent-child agreement using chronic-generic compared to generic measurements. Parents seem to be more easily able to empathize with their child about condition-specific aspects of daily life. This might be because parents and children regularly discuss the disease and the stresses and challenges in everyday life. Aspects of generic HRQOL seem not to be as relevant as disease-specific aspects in family life. The HRQOL measurement should be selected and used depending on the target. Condition-specific questionnaires have the advantage to be more sensitive. Therefore, they should be used to evaluate quality of life changes in a clinical trial, after surgical treatment or psychosocial interventions. Generic HRQOL measurements allow the use in healthy as well 
as clinical populations regardless of the health condition status and enable comparison between different health conditions as well as comparisons with healthy reference populations [23].

Also, our results showed that fathers tended to overrate children's condition-specific HRQOL in the domain Social. The domain Social assess aspects of bullying and social exclusion due to EA. Adolescents behave differently towards their parents and interpret parental behavior differently, depending on whether they interact with their mother or their father [63]. We assume that the differences in the parental perception of the condition-specific domain Social might be due to differences in the mother-child, respectively father-child relationship [64]. Adolescents might talk about experiences of bullying and social exclusion more often or more openly with their mothers [65].

Mothers and fathers of children and adolescents take on distinctive tasks regarding the development of their child $[64,66]$. This might explain the differences between the agreement of mother-child-reports and father-child-reports. Although mothers are typically the primary caregiver when the child has special health care needs, fathers of children with developmental delays or physical illness are more highly involved in the daily care than fathers of healthy children [67]. Fathers of children with chronic diseases showed an increase of involvement $[68,69]$ and therefore the high agreement between mothers and fathers of our sample might be explained by high involvement and interest of the participating fathers in health and development of the children.

In summary, while more work remains, our results present the first evidence of high inter-parental agreement on children's HRQOL in patients born with EA over almost all domains of HRQOL for both generic and condition-specific HRQOL. Since in our study, we examined only a small sample of patients born with EA and their parents, the results may only be interpreted as first tendencies. Still, there is not enough evidence that allows replacing mother and father reports even though the inter-parental agreement was high, esp. when using condition-specific HRQOL measurements. A systematic inclusion and evaluation of the triadic family system is necessary to get a comprehensive and entire view of the children's health.

\section{Limitations}

Since almost all families that participated had two parents living in the same household, findings of this study might not be representative (e.g., the situation single parents might differ). The stressors in this kind of families might be quantitatively as well as qualitatively different, considering that less communication might take place between both parents. Reports from mothers and fathers could also largely differ depending on who is looking after the child for which period. This aspect should be considered in future studies. Due to the small sample size, we were not able to control for the age of the child, child's gender or severity level of disease.

Another limitation applying to the findings, in general, is that no control was undertaken on social desirability effects. For instance, parents might have reported a higher HRQOL than the actual one. This suggestion derives from the fact that the parents were recruited from the medical clinic at which their children are treated. Parents would probably be refrained from expressing negative attitudes that might indirectly involve the doctor; it would be rather more acceptable for them to report as if things are generally going moderately well. Since the families filled out the questionnaires in a home environment, we cannot exclude that parents and children coordinated their answers even though they had explicitly been asked not to talk to each other while answering the questionnaires. The results of this study can be used as an indication for future studies investigating the triadic agreement between mothers, fathers, and children with rare malformations such as EA.

\section{Conclusions}

The findings of the present study are important in the context of providing information on HRQOL of German children born with EA from mothers', fathers', and children's' perspectives.' Results show that mothers' and fathers' reports correspond to each other.

Nonetheless, these reports might not be interchangeably used because of mother-child and father-child agreement reveal differences. Children might know the best on how they feel, and parent proxy-report is recommended when reasons such as young age, illness, or cognitive impairments do not allow to ask the child. But parent-reports no matter whether mother or father - should only be an additional source to broaden the view on the child's health status and well-being.

To conclude, the current study contributes to the different perspectives when parenting a child born with EA. The study's unique contributions include an examination of the strong inter-parental agreement on HRQOL involving multiple members' perspectives. This provides empirical evidence for how three family members with different perceptions can be combined to study the "whole" family and HRQOL.

\footnotetext{
Abbreviations

ANOVA: Analysis of variance; Cl: Confidence interval; EA: Esophageal atresia; EA-QOLC: Esophageal Atresia - Quality of Life Questionnaires; F: F-value; HRQOL: Health-related quality of life; ICC: Intraclass correlation coefficient; M: Mean; MHH: Medical School Hannover; p: P-value; PedsQL ${ }^{\text {TM. }}$ Pediatric Quality of Life Inventory TM; PROs: Patient-reported outcomes; SD: Standard deviations; UKE: University Medical Center Hamburg-Eppendorf
} 


\section{Acknowledgments}

We want to thank Maike Heise, who assisted in data collection and data analysis, Sofie Flieder, who supported in recruiting families and collection data and Barbara Dammeier-Goméz, who helped us in recruiting families with children and adolescents and of course all participating families who shared their experiences with us.

\section{Financial disclosure}

All authors confirm that they have no financial relationships relevant to this study and its results to disclose.

\section{Authors' contributions}

SW analyzed and interpreted the data and was a major contributor in writing the manuscript. JB, MB, JD, MDB, and JQ contributed in writing of the paper. All authors read and approved the final manuscript.

\section{Funding}

Not applicable.

\section{Availability of data and materials}

The datasets used and/or analyzed during the current study are available from the corresponding author on reasonable request.

\section{Ethics approval and consent to participate}

This study was approved by the Ethic Review Board of Hannover, Germany (2936-2015). All participants gave their written informed consent to participate in the study.

\section{Consent for publication}

Not applicable.

\section{Competing interests}

The authors declare that they have no competing interests.

\section{Author details}

${ }^{1}$ Department of Medical Psychology, University Medical Center Hamburg-Eppendorf, Center for Psychosocial Medicine, Martinistraße 52, W 26, 20246 Hamburg, Germany. ${ }^{2}$ Hannover Medical School, Center of Pediatric Surgery, Carl-Neuberg-Str. 1, 30625 Hannover, Germany. ${ }^{3}$ Department of Pediatric Surgery, The Queen Silvia Children's Hospital, 41685 Gothenburg, Sweden.

Received: 24 April 2019 Accepted: 29 August 2019

\section{Published online: 11 September 2019}

\section{References}

1. Wang B, Tashiro J, Allan BJ, Sola JE, Parikh PP, Hogan AR, et al. A nationwide analysis of clinical outcomes among newborns with esophageal atresia and tracheoesophageal fistulas in the United States. J Surg Res. 2014;190(2):604-12.

2. Oddsberg J, Lu Y, Lagergren J. Aspects of esophageal atresia in a population-based setting: incidence, mortality, and cancer risk. Pediatric surgery international. Pediatr Surg Int. 2012;28(3):249-57.

3. Sfeir R, Bonnard A, Khen-Dunlop N, Auber F, Gelas T, Michaud L, et al. Esophageal atresia: data from a national cohort. J Pediatr Surg. 2013; 48(8):1664-9.

4. Lilja H, Wester T. Outcome in neonates with esophageal atresia treated over the last 20 years. Pediatr Surg Int. 2008;24(5):531-6.

5. ljsselstijn $H$, Van Beelen NWG, Wijnen RMH. Esophageal atresia: long-term morbidities in adolescence and adulthood. Dis Esophagus. 2013;26:417-21.

6. Chetcuti P, Phelan P. Respiratory morbidity after repair of oesophageal atresia and tracheo-oesophageal fistula. Arch Dis Child. 1993;68(2):167-70.

7. Tovar JA, Diez Pardo JA, Murcia J, Prieto G, Molina M, Polanco I. Ambulatory 24-hour manometric and $\mathrm{pH}$ metric evidence of permanent impairment of clearance capacity in patients with esophageal atresia. J Pediatr Surg. 1995;30(8):1224-31.

8. Sistonen SJ, Koivusalo A, Nieminen U, Lindahl H, Lohi J, Kero M, et al. Esophageal morbidity and function in adults with repaired esophageal atresia with tracheoesophageal fistula: a population-based long-term follow-up. Ann Surg. 2010;251(6):1167-73.

9. Koivusalo A, Pakarinen MP, Rintala RJ. The cumulative incidence of significant gastrooesophageal reflux in patients with oesophageal atresia with a distal fistula--a systematic clinical, pH-metric, and endoscopic follow-up study. J Pediatr Surg. 2007:42(2):370-4.

10. Spitz L. Esophageal atresia. Lessons I have learned in a 40-year experience. J Pediatr Surg. 2006;41(10):1635-40.

11. Gottrand F, Sfeir R, Coopman S, Deschildre A, Michaud L. Outcome of children with repaired oesophageal atresia. Arch Pediatr. 2008;15(12): 1837-42.

12. Pedersen RN, Markow S, Kruse-Andersen S, Qvist N, HAnsen TP, Gerke $O$, et al. Esophageal atresia: gastroesophageal functional follow-up in 5-15 year old children. J Pediatr Surg. 2013;48:2487-95.

13. Malmström K, Lohi J, Lindahl H, Pelkonen A, Kajosaari M, Sarna S, et al. Longitudinal follow-up of bronchial inflammation, respiratory symptoms, and pulmonary function in adolescents after repair of esophageal atresia with tracheoesophageal fistula. J Pediatr. 2008;153(3):396-401.

14. Little D, Rescorla F, Grosfeld J, West K, Scherer L, Engum S. Long-term analysis of children with esophageal atresia and tracheoesophageal fistula. J Pediatr Surg. 2003;38(6):852-60.

15. Gatzinsky V, Jönsson L, Ekerljung L, Friberg L, Wennergren G. Longterm respiratory symptoms following oesophageal atresia. Acta Paediatr. 2011;100(9):1222-5.

16. Chittmittrapap S, Spitz L, Kiely E, Brereton R. Oesophageal atresia and associated anomalies. Arch Dis Child. 2011;64(3):364-80.

17. Harmer M, Wootton S, Gilbert R, Anderson C. Association of nutritional status and health-related quality of life in children with chronic kidney disease. Qual Life Res. 2019;28(6):1565-73.

18. Dellenmark-Blom M, Chaplin JE, Gatzinsky V, Jonsson L, Abrahamson K. Health-related quality of life among children, young people and adults with esophageal atresia: a review of the literature and recommendations for future research. Qual Life Res. 2015;24(10):2433-45.

19. Dellenmark-Blom M, Abrahamsson K, Quitmann JH, Sommer R, Witt S, Dingemann J, et al. Development and pilot-testing of a condition-specific instrument to assess the quality-of-life in children and adolescents born with esophageal atresia. Dis Esophagus. 2017;30(7):1-9.

20. Dellenmark-Blom M, Dingemann J, Witt S, Quitmann JH, Jonsson L, Gatzinsky V, et al. The esophageal-atresia-quality-of-life questionnaires: feasibility, validity and reliability in Sweden and Germany. J Pediatr Gastroenterol Nutr. 2018;67(4):469-77.

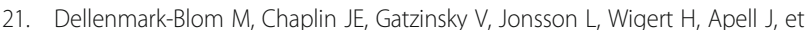
al. Health-related quality of life experiences among children and adolescents born with esophageal atresia: development of a conditionspecific questionnaire for pediatric patients. J Pediatr Surg. 2016;51(4):563-9.

22. Flieder S, Dellenmark-Blom M, Witt S, Dingemann C, Quitmann JH, Jonsson $L$, et al. Generic health-related quality of life after repair of esophageal atresia and its determinants within a German-Swedish cohort. Eur J Pediatr Surg. 2019;29(1):75-84.

23. Haverman L, Limperg P, Young N, Grootenhuis M, Klaassen R. Paediatric health-related quality of life: what is it and why should we measure it? Arch Dis Child. 2017;102(5):393-400.

24. Eiser C, Morse R. Can parents rate their child's health-related quality of life. Results of a systematic review. Qual Life Res. 2001;10:347-57.

25. Mulligan K, Etheridge A, Kassoumeri L, Wedderburn LR, Newman S. Do mothers and fathers hold similar views about their child's arthritis? Arthritis Rheum. 2009:61(12):1712-8.

26. Bullinger M, Ravens-Sieberer U. Grundlagen, Methoden und Anwendungsgebiete der Lebensqualitätsforschung bei Kindern. Prax Kinderpsychol Kinderpsychiatr. 1995;44(10):391-8.

27. Bullinger M, Quitmann J. Quality of life as patient-reported outcomes: principles of assessment. Dialogues Clin Neurosci. 2014;16(2):137-45.

28. Bevans KB, Riley AW, Moon J, Forrest CB. Conceptual and methodological advances in child-reported outcomes measurement. Expert Rev Pharmacoecon Outcomes Res. 2010;10(4):385-96.

29. Varni JW, Limbers CA, Burwinkle TM. How young can children reliably and validly self-report their health-related quality of life?: an analysis of 8,591 children across age subgroups with the PedsQL 4.0 generic core scales. Health Qual Life Outcomes. 2007;5:1.

30. Cremeens J, Eiser C, Blades M. Characteristics of health-related self-report measures for children aged three to eight years: a review of the literature. Qual Life Res. 2006;15(4):739-54.

31. Rajmil L, Rodriguez López A, López-Aguilà S, Alonso J. Parent-child agreement on health-related quality of life (HRQOL): a longitudinal study. Health Qual Life Outcomes. 2013;11(101):1-10. 
32. De Los Reyes A, Augenstein TM, Wang M, Thomas SA, Drabick DAG, Burgers $\mathrm{DE}$, et al. The validity of the multi-informant approach to assessing child and adolescent mental health. Psychol Bull. 2015;141(4):858-900.

33. Achenbach TM, McConaughy SH, Howell CT. Child/adolescent behavioral and emotional problems: implications of cross-informant correlations for situational specificity. Psychol Bull. 1987;101(2):213-32.

34. Stanger $\mathrm{CL}$, Agreement M. Among parents, teachers, and children an Internaliznig and externalizing behavior problems. J Clin Child Psychol. 1993;22(1):107-16

35. Becker SP, Isaacson PA, Servera M, Saez B, Burns GL. Mother-father agreement and one-year stability of children's sleep functioning. Sleep Med. 2017:36:29-34.

36. Jensen PS, Xenakis SN, Davis H, Degroot J. Child psychopathology rating scales and interrater agreement: II. Child and family characteristics. J Am Acad Child Adolesc Psychiatry. 1988;27(4):451-61.

37. Duhig AM, Renk K, Epstein MK, Phares V. Interparental agreement on internalizing, externalizing, and total behavior problems: a meta-analysis. Clin Psychol Sci Pract. 2000;7:435-53.

38. Jozefiak T, Larsson B, Wichstrom L, Mattejat F, Ravens- Sieberer U. Quality of life as reported by school children and their parents: a cross-sectional survey. Health Qual Life Outcomes. 2008;6(34):1-11.

39. Varni JW, Limbers C, Burwinkle TM. Literature review: health-related quality of life measurement in pediatric oncology: hearing the voices of the children. J Pediatr Psychol. 2007;32(9):1151-63.

40. Sprangers MA, Aaronson NK. The role of health care providers and significant others in evaluating the quality of life of patients with chronic disease: a review. J Clin Epidemiol. 1992;45(7):743-60.

41. Eiser C, Varni JW. Health-related quality of life and symptom reporting: similarities and differences between children and their parents. Eur J Pediatr. 2013;172(10):1299-304.

42. Upton $\mathrm{P}$, Lawford J, Eiser C. Parent-child agreement across child health-related quality of life instruments: a review of the literature. Qual Life Res. 2008;17:895-913.

43. Panepinto JA, O'Mahar KM, DeBaun MR, Loberiza FR, Scott JP. Health-related quality of life in children with sickle cell disease: child and parent perception. Br J Haematol. 2005;130(3):437-44.

44. Varni JW, Burwinkle TM, Lane MM. Health-related quality of life measurement in pediatric clinical practice: an appraisal and precept for future research and application. Health Qual Life Outcomes. 2005:3:34.

45. Varni JW, Seid M, Kurtin P. PedsQL 4.0 TM: reliability and validity of the pediatric quality of life inventory TM version 4.0 generic core scales in health and patient populations. Med Care. 2001;39:800-12.

46. IBM SPSS Statistics 25. SPSS for windows, version 25.0. Chicago: SPSS Inc:; 2017

47. Koo TK, Li MY. A guideline of selecting and reporting Intraclass correlation coefficients for reliability research. J Chiropr Med. 2016;15(2):155-63.

48. Cicchetti D. Guidelines, criteria, and rules of thumb for evaluating normed and standardized assessment instruments in psychology. Psychol Assess. 1994;6(4):284-90.

49. Landis JR, \& Koch GG, (1977). Measurement of Observer Agreement for Categorical Data. Biometrics, 33(1), 159-174. https://doi.org/10.2307/2529310

50. Falt E, Wallby T, Sarkadi A, Salari R, Fabian H. Agreement between mothers', fathers', and teachers' ratings of behavioural and emotional problems in 3-5-year-old children. PLoS One. 2018;13(11):e0206752.

51. Lee $\mathrm{Y}$-C, Yang $\mathrm{H}-\mathrm{J}$, Lee $\mathrm{W}-\mathrm{T}$, Teng $\mathrm{M}-\mathrm{J}$. Do parents and children agree on rating a child's HRQOL? A systematic review and Meta-analysis of comparisons between children with attention deficit hyperactivity disorder and children with typical development using the PedsQLTM. Disabil Rehabil. 2019;41(3):265-75. https://doi.org/10.1080/09638288.2017.1391338.

52. Aalgaard Kelly G. Development and examination of a family triadic measure to examine quality of life family congruence in nursing home residents and two family members. Gerontol Geriatr Med. 2015;1:2333721415611562.

53. Aalgaard KG. Quality of life in nursing homes: a theoretical and empirical review. Great Plains Sociol. 2013;23:33-63.

54. Challinger $Y$, Julious S, Watson R, Philp I. Quality of care, quality of life and the relationship between them in long-term care institutions for the elderly. Int J Geriatr Psychiatry. 1995;11:883-8.

55. Lawton MP. Measures of quality of life and subjective well-being. Generations. 1997:2:45-7.

56. Weitkamp K, Daniels J, Rosenthal S, Romer G, Wiegand-Grefe S. Health-related quality of life: cross-informant agreement of father, mother, and self-report for children and adolescents in outpatient psychotherapy treatment. Child Adolesc Mental Health. 2013;18(2):88-94.

57. Dave S, Nazareth I, Senior R, Sherr L. A comparison of father and mother report of child behaviour on the strengths and difficulties questionnaire. Child Psychiatry Hum Dev. 2008;39(4):399-413.

58. Sollie H, Larsson B, Morch WT. Comparison of mother, father, and teacher reports of $A D H D$ core symptoms in a sample of child psychiatric outpatients. J Atten Disord. 2013;17(8):699-710.

59. Mascendaro PM, Herman KC, Webster-Stratton C. Parent discrepancies in ratings of young children's co-occurring internalizing symptoms. Sch Psychol Q. 2012;27(3):134-43.

60. Kalyva E, Melonashi E. Parental perceptions of health-related quality of life of Albanian children with epilepsy. Health Psychol Res. 2015;3(2):2244

61. Ringold S, Wallace CA, Rivara FP. Health-related quality of life, physical function, fatigue, and disease activity in children with established polyarticular juvenile idiopathic arthritis. J Rheumatol. 2009;36(6):1330-6.

62. Silva N, Bullinger M, Quitmann J, Ravens-Sieberer U, Rohenkohl A. HRQoL of European children and adolescents with short stature as assessed with generic (KIDSCREEN) and chronic-generic (DISABKIDS) instruments. Expert Rev Pharmacoecon Outcomes Res. 2013;13(6):817-27.

63. Dimler LM, Natsuaki MN, Hastings PD, Zahn-Waxler C, Klimes-Dougan B. Parenting effects are in the eye of the beholder: parent-adolescent differences in perceptions affects adolescent problem behaviors. J Youth Adolesc. 2017:46(5):1076-88.

64. Seiffge-Krenke I. Väter: Notwendig, überflüssig oder sogar schädlich für die Entwicklung ihrer Kinder? In: Seiffge-Krenke I, editor. Psychotherapie und Entwickungspsycholgie, vol. 2. Heidelberg: Springer Medizin Verlags; 2009. p. 193-222.

65. Shulman S, Seiffge-Krenke I. Fathers and adolescents. Developmental and clinical perspectives. London, New York: Routledge; 1997.

66. Fabiano GA, Caserta A. Future directions in father inclusion, engagement, retention, and positive outcomes in child and adolescent research. J Clin Child Adolesc Psychol. 2018;47(5):847-62.

67. Yogman M, Garfield CF. Fathers' roles in the care and development of their children: the role of pediatricians. Pediatrics. 2016;138(1). https://doi.org/10. 1542/peds.2016-1128.

68. Chesler MA, Parry C. Gender roles and/or styles in crisis: an integrative analysis of the experiences of fathers of children with cancer. Qual Health Res. 2001;11(3):363-84

69. McNeill T. Fathers' experience of parenting a child with juvenile rheumatoid arthritis. Qual Health Res. 2004;14(4):526-45.

\section{Publisher's Note}

Springer Nature remains neutral with regard to jurisdictional claims in published maps and institutional affiliations.

Ready to submit your research? Choose BMC and benefit from:

- fast, convenient online submission

- thorough peer review by experienced researchers in your field

- rapid publication on acceptance

- support for research data, including large and complex data types

- gold Open Access which fosters wider collaboration and increased citations

- maximum visibility for your research: over $100 \mathrm{M}$ website views per year

At $\mathrm{BMC}$, research is always in progress.

Learn more biomedcentral.com/submissions 